\title{
Teaching Reform and Exploration of General Ecology
}

\author{
Maojuan Zhou
}

Qilu University of Technology(Shandong Academy of Sciences)

School of Environmental Science \& Engineering

No.3501, Daxue Road, Changqing District, Jinan, Shandong, 250353, China

Abstract: In the teaching work, experimental teaching is an important part, which plays a vital role in the cultivation of students' practical innovation ability and comprehensive quality. This article analyzes the existing problems in ecological experimental teaching and proposes new ideas for reform, Cultivate students' sense of innovation and innovative ability, and stimulate students' enthusiasm and initiative in ecology learning.

Keywords: General Ecology; Teaching Reform; Exploration

As a cross-discipline ecology, it is of great significance to environmental protection, resource development and ecological restoration. Many colleges and universities have adopted it as the main course of their majors. At present, a series of reforms in ecological experiments have been carried out in the country. However, there are still a series of problems, which lead to insufficient hands-on analysis and problem-solving ability of students. It can be seen that reforming the ecological experimental teaching model and exploring scientific and reasonable experimental projects is urgent.

\section{Promote participatory teaching and realize flexible teaching methods}

\subsection{Class discussion}

Discussions and exchanges in the classroom, on the one hand, can cultivate students' sense of teamwork, on the other hand, they can also help to promote students' independent thinking and independent problem-solving ability. This is an important way to enhance the effectiveness of classroom teaching. Before formal classroom discussions Teachers can formulate relevant topics based on the teaching content, and then divide the students into several groups, encourage students to find relevant information in their own way, and then summarize the collected information, and each group can make a complete outline and discuss In the process, free debate is advocated. Teachers observe the students' thinking, and gradually make students discover the core of the problem and have different opinions. Through free debate, students' thinking ability and observation ability can be effectively improved. For example, in the process of explaining the content of solid pollutants, teachers can prepare questions related to the course content before class, "Can the popularization of paid plastic bags solve white pollution?" Divided into two opposites, the debate summed up the solution to white pollution, and some students have a strong awareness of ecological protection, saying that plastic bags are not used or used as little as possible to ensure that the ecological environment is not destroyed. Such a method can deepen it on the one hand Students' theoretical knowledge can also significantly improve students' language expression skills and logical thinking skills.

\subsection{Case analysis}

When explaining the teaching content, you can choose cases that are similar to the content. Case analysis can deepen students' memory on the one hand, and on the other hand help students integrate theoretical knowledge and practical

Copyright (C) 2020 Maojuan Zhou

doi: 10.18282/le.v9i7.1521

This is an open-access article distributed under the terms of the Creative Commons Attribution Non-Commercial License

(http://creativecommons.org/licenses/by-nc/4.0/), which permits unrestricted non-commercial use, distribution, and reproduction in any medium, provided the original work is properly cited. 
thinking. The choice of cases should be as simple as possible Intuitive, when discussing the case, the teacher should return the main position of the classroom to the students, so that the students can grasp the rhythm of the classroom, and find the problem and solve it properly in the process of teacher-student interaction.

For example, in the teaching process of air pollution, teachers can introduce cases of haze weather, use multimedia assisted teaching equipment to play documentaries, and randomly hand them to different student groups based on questions. What is haze? The harm of smog? How to solve the smog? The reason for this is that the emergence of haze weather in recent years is closely related to the problem of air pollution. For case analysis, students can think in conjunction with real life, which not only concentrates students' attention, but also enables students to actively participate In conversation.

This case not only fits the content of the textbook, but also reflects the representative problems in environmental protection, enabling students to view problems from multiple perspectives while mastering theoretical knowledge, effectively training students' thinking skills, and training students to solve problems Ability.

\section{Use multimedia assisted teaching technology to modernize teaching}

\subsection{Picture and animation display}

In order to improve the flexibility of the general ecology classroom and avoid vague teaching and omissions in explanation, teachers can introduce pictures and animations that match the teaching content in the teaching, which can enhance the teaching quality while activating the teaching atmosphere. For example, "Tropical Rain Forest" teaching. Teachers can download some real pictures of the rainforest from the Internet to intersperse into the courseware, so that the teacher's explanation will be more vivid.

\subsection{Film appreciation}

In ordinary ecological teaching, there will be many contents closely related to real life, and these contents are also reflected in many films. At this time, teachers can use related films to strengthen students' understanding of knowledge points and increase students' interest in learning. For example, "global environment" teaching. In this class, teachers can introduce the film "The Truth That Cannot Be Ignored". The stories and scenes described in this film are mainly developed around the topic of global warming. Disaster scenarios caused by warming are displayed. Students can understand the causes of global warming and its possible consequences through this film, so that students can pay attention to environmental protection in their daily lives and consciously control carbon emissions. . When choosing a film, we should pay attention to the fit between the film and the teaching content, and after the film is played, discuss and evaluate the content of the film with the students, so as to broaden the students' horizons while achieving the teaching goals.

\subsection{Micro-class teaching}

Micro-course teaching is a new type of teaching form that uses short videos as teaching media with the support of information technology. It mainly focuses on teaching important knowledge points in teaching to improve the convenience of students' learning. Students can learn on the Internet through mobile terminals, thereby fragmenting learning time and improving students' learning benefits. At the same time, micro-class teaching also breaks the shackles of learning time and space, so that students' learning environment is no longer just a classroom, and it improves the freedom and flexibility of learning. Teachers can transfer the learning content of general ecology to the network platform in the form of micro-classes, allowing students to allocate time to learn them independently, and receive students' feedback and self-evaluation through the online platform, and provide timely help and guide.

\section{Concluding remarks}

Under the background of the new curriculum reform, education pays more and more attention to the cultivation of students' abilities, which also urges the general ecology teaching to carry out innovative reforms. Through the optimization of teaching concepts and teaching methods, the education effect of general ecology teaching is improved. . In daily teaching, teachers should integrate the concept of student-centeredness, through more diversified teaching 
methods, improve students' classroom participation, so that students maintain a high degree of enthusiasm for learning, so that the educational goals of general ecology teaching can be better realized.

\section{References}

1. Wen Yifu, Bi Yufen, Luo Fucheng, Chen Gong, Shan Guilian, Zhao Xiaoxue, Duan Xinhui, Han Bo. Teaching reform and exploration of general ecology[J]. Journal of Yunnan Agricultural University (Social Sciences), 2019,13 (03):132-136.

2. Tian Xun, Wang Cong. Exploration on the teaching reform of general ecology course[J]. Journal of Inner Mongolia University for Nationalities (Natural Science Edition), 2015, 30(04): 327-328+332+369.

3. Zhu Fan, Wang Guangjun, Xiang Wenhua, Yan Wende. Exploration on the teaching reform of general ecology experiment course[J]. Journal of Central South University of Forestry and Technology (Social Science Edition), 2010, 4(04): 162-163. 